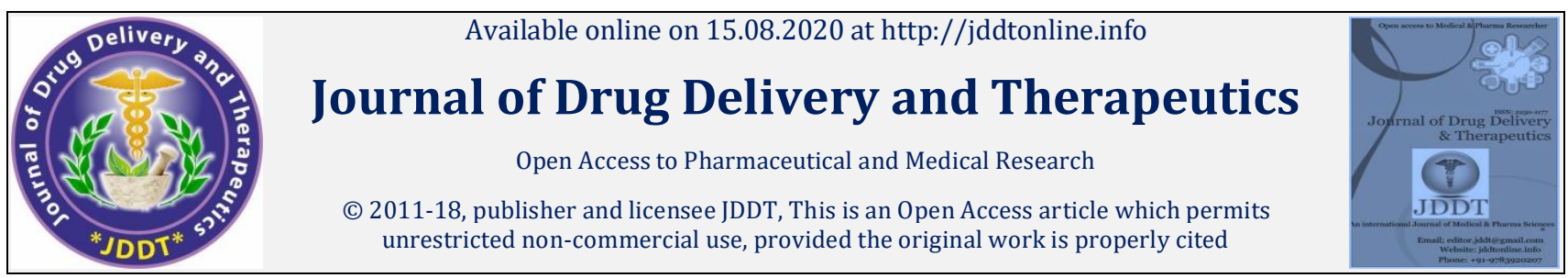

Open $\odot$ Access

Research Article

\title{
A Study to Evaluate Pharmacoeconomics of Antihypertensive Drugs in a Tertiary Care Teaching Hospital
}

\author{
Nimmy N John*, Athira Krishnan, JV Midhun, Riya Juan \\ Department of Pharmacy Practice, Net Pharmacy College, Raichur-584103 Karnataka, India
}

\begin{abstract}
Background: Hypertension is a major public health problem associated with large health burden as well as high economic burden at individual and population levels. A prospective observational study carried out in in-patients admitted to general medicine department of tertiary care hospital to evaluate the most cost effective therapy among the monotherapy of Amlodipine and combination therapy of telmisartan + hydrochlorthiazide.
\end{abstract}

Methods: A total of 120 Hypertensive patients case records prescribed with monotherapy of Amlodipine and combination therapy of Telma $\mathrm{H}$ were reviewed and evaluated using descriptive statistics and ' $p$ ' value and assessed for their financial burden based on the cost per tablet for an year, Cost effectiveness ratio for the patients with controlled Blood Pressure by using a particular drug.

Results: Out of 120 patients females were more (59.2\%) and most of them were under the age group of 41-60 years. Majority of the patients had a known history of hypertension (65\%). Most of the patients were prescribed with Telma H 40/12.5mg (40\%) followed with Amlong $5 \mathrm{mg}$ $(35.8 \%)$. There was a significant positive correlation (i.e., $\mathrm{p}$ value $=0.05$ ) between persistence patterns of patients with drug therapy. Probability of patients with controlled Blood Pressure taking Amlong $10 \mathrm{mg}$ were $82.35 \%$ followed by patients with Amlong $5 \mathrm{mg}$.

Conclusion: This study clearly showed that monotherapy of amlodipine is the most cost effective therapy than combination therapy of Telma $\mathrm{H}$ in order to reduce financial burden to the patient as well as to decrease the complications.

Keywords: Hypertension, Pharmacoeconomics, Cost effectiveness, Blood Pressure.

Article Info: Received 18 June 2020; Review Completed 26 July 2020; Accepted 06 August 2020; Available online 15 August 2020

Cite this article as:

John NJ, Krishnan A, Midhun JV, Juan R, A Study to Evaluate Pharmacoeconomics of Antihypertensive Drugs in a Tertiary Care Teaching Hospital, Journal of Drug Delivery and Therapeutics. 2020; 10(4-s):176-180

http://dx.doi.org/10.22270/jddt.v10i4-s.4227

ㅁ.

Mrs. Nimmy N John, Department of Pharmacy Practice, NET Pharmacy College, Raichur- 584103, Karnataka, India

\section{ABBREVIATIONS}

BP: Blood Pressure; ARB: Angiotensin Receptor Blocker; CCB: Calcium Channel Blocker; ACEI: Angiotensin Converting Enzyme Inhibitor; JNC: Join National Committee

\section{INTRODUCTION}

Uncontrolled hypertension is a big medical and psychosocial problem in developed as well as developing countries. Global prevalence of adult hypertensive patients was about $22 \%$ in 2014. ${ }^{1}$ Hypertension affects 1 billion individuals worldwide and is expected to increase by $29 \%$ to reach 1.6 billion by 2025. The overall prevalence is around $29.6 \%$ with regional variation in rural $(27.6 \%)$ and urban $(33.8 \%)$ population. ${ }^{2}$ In conjunction with primary casual factor a number of adjunctive factors such as, emotional stress, sedentary life style and low potassium intake may increase the probability of developing HTN, hence on a similar dietary salt, some individuals develop HTN while others do not and the probability to develop hypertension depends on the individuals weight of hypertensions adjunctive factors. ${ }^{3}$

Hypertension treatment starts with therapeutic lifestyle changes for all individuals with hypertension and prehypertension. Decisions on pharmacological treatment are based on global vascular risks and not on the level of blood pressure. In patients with newly diagnosed uncomplicated hypertension and no compelling indications, the choice of first line monotherapy includes angiotensin converting enzyme inhibitors (ACEIs), angiotensin receptor blockers (ARBs), calcium channel blockers (CCBs), and diuretics. ${ }^{4}$ 
Hypertension is the number one risk factor for cardiovascular disease in worldwide and thus has emerged as a major public health concern. In addition to the large health burden, there is an enormous financial burden associated with the disease. This is because the treatment of hypertension requires an investment over many years to ensure disease free years among those affected. 5

The global burden of disease is increasing steeply and expenditure for hypertension is on the increase in developed countries, and potentially also in the developing world. The population and the high-risk approach to hypertension control also have economic consequences; these may vary in different societies and need to be assessed to ensure appropriate allocation of resources. ${ }^{6}$

The choice of drug therapy is of great importance for the total treatment cost, since the cost varies significantly between different drugs. This is because the treatment of hypertension requires an investment over many years to ensure disease free years among those affected. 4

The objective of the research is to evaluate the most cost effective therapy among the different groups of antihypertensive drugs like monotherapy of amlodipine and combination of telmisartan + hydrochlorthiazide prescribed in the tertiary care hospital.

\section{MATERIALS \& METHODS}

\section{Research design:}

The study was carried out for a period of six months. A prospective observational study was carried out by reviewing prescriptions of 120 patients who have been prescribed with Monotherapy of Amlodipine and combinational therapy of Telma $\mathrm{H}$ for treating Hypertension. The study was started after taking consent from respective authorities.

\section{Subjects:}

\section{Inclusion criteria:}

- $\quad$ Hypertensive patients prescribed with monotherapy of amlodipine and combination therapy of telmisartan with hydrochlorthiazide
- Hypertensive patients between 20 years and 80 years of age and both genders

- Hypertensive patients alone and with co-morbidities (hypothyroidism, diabetes, dyslipidemia, coronary artery disease and myocardial infraction)

\section{Exclusion criteria:}

- Pregnant and lactating women

- Patients with any co-morbidity such as renal transplant patients and malignancy conditions.

A predesigned data entry form was used as a study tool to enter all patient details, which include patient information, reason for admission, past medical history, social history, laboratory investigation, medications prescribed, cost per tablet, monthly cost and annual cost of the drug. Data was analysed using descriptive statistics namely total numbers, percentage and monetary unit such as Rupees were used to represent the cost of a drug.

\section{Materials used:}

\section{Data entry form}

\section{Statistical method:}

- The demographic data, disease data and drug data of the patients were analyzed. Data was analyzed using descriptive statistics namely total numbers, percentage, to represent Pharmacoeconomics

\section{RESULTS}

A total number of 120 case sheets of hypertensive patients prescribed with amlodipine monotherapy and telmisartan with hydrochlorthiazide combination therapy were reviewed and analyzed.

\section{Tables:}

Table 1 shows demographics and characteristics of patients by class of drug prescribed at enrollment. Out of 120 subjects $43(35.83 \%)$ patients were taking Amlong 5mg.According to gender classification more female patients were taking Amlong 5mg (20.83\%). Most of the patients with heart diseases were taking Amlong $5 \mathrm{mg}$ and $10 \mathrm{mg}$ (1.7\%).

Table 1: Demographics \&characteristics of patients by class of drugs prescribed $(n=120$

\begin{tabular}{|c|c|c|c|c|c|}
\hline Sl.No & Characteristics $\{\mathbf{n}(\%)\}$ & Amlong 5 Mg & Amlong 10mg & Telma H 40/12.5 mg & Telma H 80/12.5 mg \\
\hline 1. & Patients & $43(35.8 \%)$ & $17(14.2 \%)$ & $48(40 \%)$ & $12(10 \%)$ \\
\hline \multirow{2}{*}{2.} & Male & $18(15 \%)$ & $6(5 \%)$ & $22(18.33 \%)$ & $2(1.7 \%)$ \\
\cline { 2 - 5 } & Female & $25(20.8 \%)$ & $11(9.2 \%)$ & $26(21.7 \%)$ & $10(8.3 \%)$ \\
\hline 4. & Patients with heart disease & $2(1.7 \%)$ & $2(1.7 \%)$ & 0 & $1(0.83 \%)$ \\
\hline
\end{tabular}

n: number of patients ; mg: milligram ; Telma H: Telmisartan + Hydrochlorthiazide 
Table 2 illustrates that most of the patients (35.8\%) were taking amlong $5 \mathrm{mg}$ and there were no significant relation between gender classification and patients with comorbidities.

Table 2: Persistence pattern for class of drugs prescribed for the patients $(n=120)$

\begin{tabular}{|c|c|c|c|c|c|c|c|}
\hline Sl.No & Characteristics & $\begin{array}{c}\text { Amlong } 5 \\
\text { mg }\end{array}$ & $\begin{array}{l}\text { Amlong } \\
10 \mathrm{mg}\end{array}$ & p value & $\begin{array}{c}\text { Telma H } \\
40 / 12.5 \mathrm{mg}\end{array}$ & $\begin{array}{c}\text { Telma H } \\
80 / 12.5 \mathrm{mg}\end{array}$ & p value \\
\hline 1. & Total patients & $43(35.8 \%)$ & $17(14.2 \%)$ & & $48(40 \%)$ & $12(10 \%)$ & \\
\hline 2. & Male & $18(15 \%)$ & $6(5 \%)$ & \multirow{2}{*}{0.640} & $22(18.33 \%)$ & $2(1.7 \%)$ & \multirow{2}{*}{0.065} \\
\hline 3. & Female & $25(20.8 \%)$ & $11(9.2 \%)$ & & $26(21.7 \%)$ & $10(8.3 \%)$ & \\
\hline 4. & $\begin{array}{l}\text { Patients with heart } \\
\text { disease }\end{array}$ & $2(1.7 \%)$ & $2(1.7 \%)$ & 0.320 & 0 & $1(0.83 \%)$ & 0.044 \\
\hline 5. & Patients with diabetics & $7(5.8 \%)$ & $6(5 \%)$ & 0.107 & $13(10.83 \%)$ & $5(4.2 \%)$ & 0.324 \\
\hline 6. & $\begin{array}{l}\text { Patients with } \\
\text { comorbidities }\end{array}$ & $22(18.3 \%)$ & $8(6.7 \%)$ & 0.774 & $21(17.5 \%)$ & $5(4.2 \%)$ & 0.570 \\
\hline
\end{tabular}

Table 3 illustrates the significance levels for the classes of drugs prescribe (Amlong, Telma H). This data suggests that there is a significant changes in the drugs among the continuers, switchers, and discontinuers. most of the patients continued their therapy with Amlodipine (23.3\%).

Table 3: Persistence pattern for class of drugs prescribed $(n=58)$

\begin{tabular}{|c|c|c|c|c|}
\hline Sl.No & Persistence patterns & Amlong $\{\mathbf{n}(\%)\}$ & Telma h $\{\mathbf{n}(\%)\}$ & P value \\
\hline 1. & Continuers & $28(23.3 \%)$ & $7(5.83 \%)$ & \multirow{2}{*}{0.029} \\
\hline 2. & Switchers & $5(4.2 \%)$ & $6(5 \%)$ & \\
\hline 3. & Discontinuers & $6(5 \%)$ & $6(5 \%)$ & \\
\hline
\end{tabular}

Table 4 illustrates a total of $35.8 \%$ of patients were taking the amlong $5 \mathrm{mg}$ tablets in which $81.40 \%$ of patients were probably controlled after this medication and the $\mathrm{C} / \mathrm{E}$ ratio is 29.38 followed with Amlong $10 \mathrm{mg}$ (CER=15.45).

Table 4: Cost effectiveness of antihypertensive treatment

\begin{tabular}{|c|c|c|c|c|c|c|}
\hline Sl.no. & Antihypertensive treatment & $\mathbf{N = 1 2 0}$ & $\begin{array}{c}\text { Cost per } \\
\text { tablet }\end{array}$ & $\begin{array}{c}\text { Patients with } \\
\text { controlled BP }\end{array}$ & $\begin{array}{c}\text { Probability } \\
\text { (effect) }\end{array}$ & CER \\
\hline 1. & Amlong 5 mg & $43(35.8 \%)$ & 2.77 & 35 & $81.40 \%$ & 29.38 \\
\hline 2. & Amlong $10 \mathrm{mg}$ & $17(14.2 \%)$ & 5.33 & 14 & $82.35 \%$ & 15.45 \\
\hline 3. & Telma H 40/12.5 mg & $48(40 \%)$ & 14.73 & 30 & $62.50 \%$ & 4.24 \\
\hline 4. & Telma H 80/12.5 mg & $12(10 \%)$ & 22.36 & 5 & $41.67 \%$ & 1.84 \\
\hline
\end{tabular}

Figure 1 shows the History of Hypertension among the patients in which $65 \%$ of the patients had known history followed with non-history (35\%).

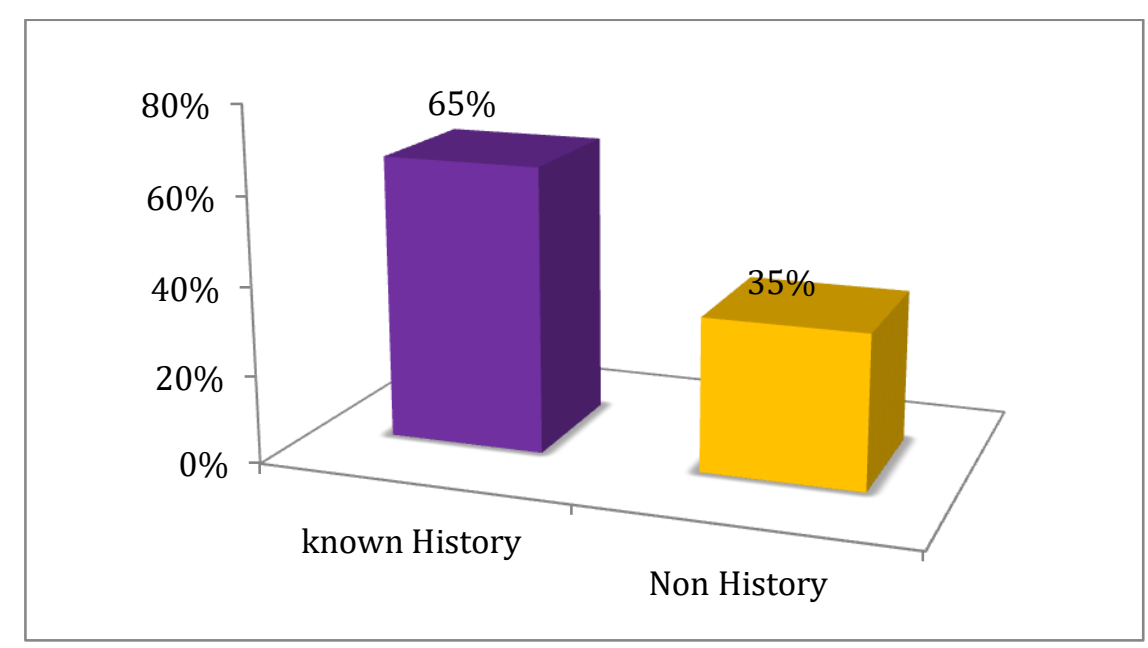

Figure 1: History of Hypertension 
Figure 2 illustrate the persistence patterns for class of drugs prescribed at enrollment. In which $28(23.33 \%)$ of patients with amlodipine continued the treatment, 5(4.2\%) switched and 6(5\%) discontinued the treatment followed with $17(14.2 \%)$ of patients with Telma $\mathrm{H}$ were continuers, $6(5 \%)$ were switchers and discontinuers

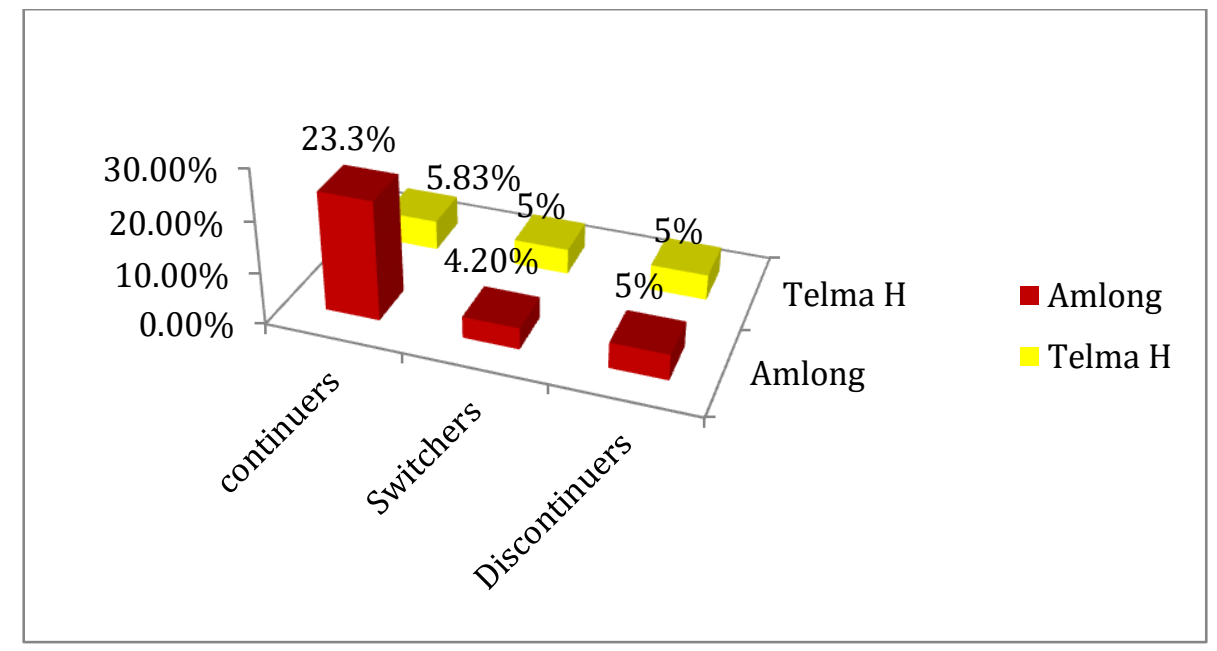

Figure 2: Persistence pattern for class of drugs prescribed

Figure 3 which shows that amlong $5 \mathrm{mg}$ tablet costs for rupees 2.65 per tablet and amlong $10 \mathrm{mg}$ costs for rupees 5.33 and telma $\mathrm{H} 40 / 12.5 \mathrm{mg}$,telma $\mathrm{H} 80 / 12.5 \mathrm{mg}$ costs for 14.73 and 22.36 rupees respectively

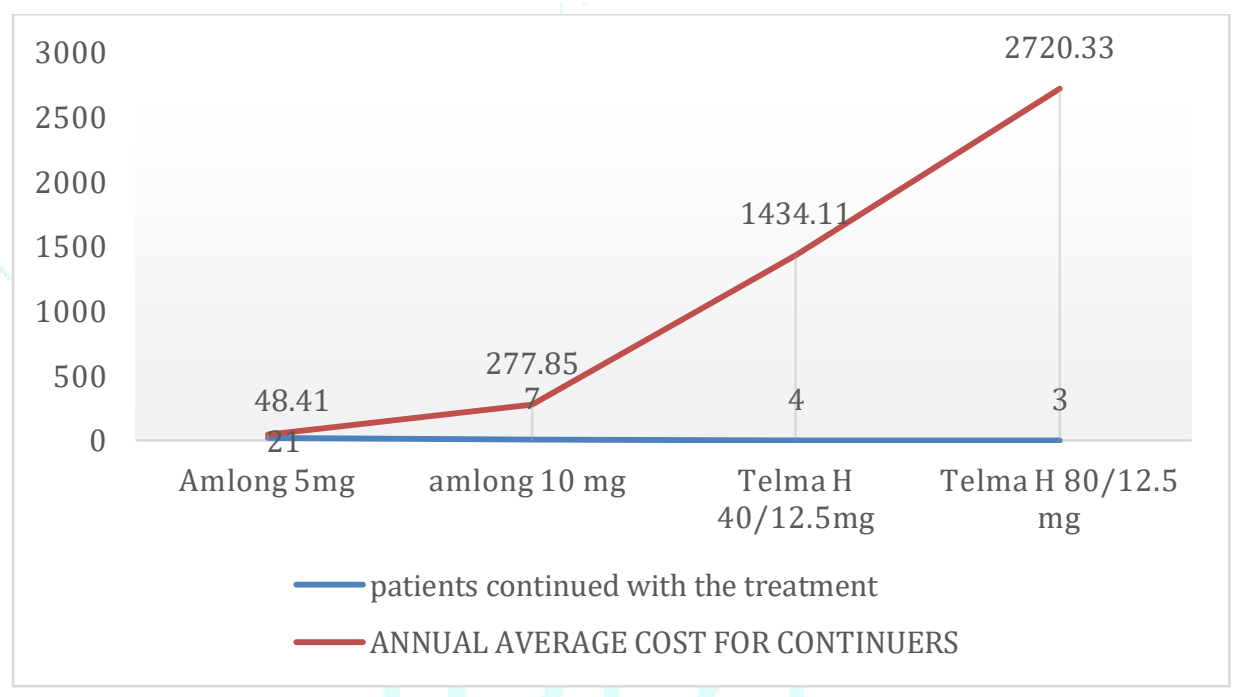

Figure 3: Annual average cost by class of drugs based on the persistence pattern.

\section{DISCUSSION}

Out of 120 patients 49 (40.8\%) were male and $71(59.16 \%)$ were female prescribed with amlodipine monotherapy and combination therapy of telmisartan with hydrochorthiazide. Obesity and menopause are the two risk factors which has linked the females with hypertension. After menopause, hormonal changes occur in the females which will contribute to the hypertension. The same results are also reported by Dhivya PS et al.

Among the total prescription collected, age was taken into consideration by dividing into 3 age groups being kept an interval of 20 years each. Maximum number of patients were found in the age group of $41-60$ years (55\%), $21-40$ years $(11.7 \%)$, and least were found in the age group of $61-80$ years $(3.33 \%)$. This data suggest that middle aged adults are at high risk of hypertension due to obesity, dyslipidemia and normal BMI. Men are more prone to hypertension than women especially below the age of 50 , after the age of 50 women are at a high risk for high blood pressure due to menopause associated with hormonal changes.
120 subjects characterized according to their social habits that is no habits and habits (both smoker and alcoholic). According to the data, patients under the category of no habits and $43(36.38 \%)$ patients comes under the category of habits. The habits like alcoholism and smoking are the major cause for hypertension; it causes vascular complications like heart diseases and stroke. The same results are also reported in Dhivya PS et al.

Table 1 shows demographics and characteristics of patients by class of drug prescribed at enrollment. Out of 120 subjects $43(35.83 \%)$ patients were taking amlong $5 \mathrm{mg}$, $17(14.1 \%)$ patients were taking amlong $10 \mathrm{mg}, 48(40 \%)$ and $12(10 \%)$ patients were taking Telma $\mathrm{H} 40 / 12.5 \mathrm{mg}$ and Telma $\mathrm{H} 80 / 12.5 \mathrm{mg}$ respectively. According to gender classification more female patients were taking amlong $5 \mathrm{mg}$ (20.83\%), Amlong $10 \mathrm{mg}$ (18.33\%), Telma H 40/12.5 mg (21.7\%), and Telma $\mathrm{H}(8.33 \%)$. There were no patients with heart diseases who was taking Telma H 40/12.5mg \& Telma $\mathrm{H} 80 / 12.5 \mathrm{mg}$. 7(5.83\%) and $6(5 \%)$ of patients with diabetics were taking Amlong $5 \mathrm{mg} \&$ Amlong $10 \mathrm{mg}$ respectively and the patients with diabetics who was taking Telma $\mathrm{H} 40 / 12.5$ 
mg was $13(10.83 \%)$ \& Telma H $80 / 12.5$ mg was $5(4.16 \%)$. Patients in accordance with comorbidities, majority of the patients were taking Amlong 5mg (18.33\%) followed by Telma H 40/12.5 mg (17.5\%). In case of patients without comorbidities were taking Amlong 5mg 12 (10\%) followed by Telma $\mathrm{H} 40 / 12.5 \mathrm{mg} 14(11.7 \%)$. This data suggests that most of the patients are prescribed with Amlodipine.

Table 2 shows the statistical analysis for the class of drugs prescribed to the patient. The data shows the comparison between amlong $5 \mathrm{mg}$, amlong $10 \mathrm{mg}$, telma $\mathrm{H} \mathrm{40/12.5} \mathrm{mg}$ and telma $\mathrm{H} 80 / 12.5 \mathrm{mg}$. The ' $\mathrm{p}$ ' value was found out determine the significance. The patients with heart disease category only shows the significance $(0.04)$ it may be due to the cardio protective actions of Telma $\mathrm{H}$ drug. There is a high risk of discontinuation of drugs when the patients are having comorbidities, but here in the study the continuers are more than switchers and discontinuers. The same result was stated in Esposti LD et al.

Table 3 illustrates the significance levels for the class of drugs prescribes (Amlong, Telma $\mathrm{H}$ ). This data suggests that there is a significant change in the drugs among the continuers, switchers, and discontinuers. This means that the monotherapy and combination therapy are having a significant changes in their effects. Both the drugs are having good therapeutic efficacy and BP lowering effects.

The main aim of our study was to find out the cost effectiveness ratio for the monotherapy and combination therapy for the drugs. The C/E is described in Table 4. From this data we can see that a total of $35.8 \%$ of patients were taking the amlong $5 \mathrm{mg}$ tablets in which $81.40 \%$ of patients were probably controlled after this medication and the $\mathrm{C} / \mathrm{E}$ ratio is 29.38 followed with Amlong $10 \mathrm{mg}$ (CER=15.45). This data suggests that probability of controlling the BP in patients can be achieved by using Amlong $10 \mathrm{mg}$ and its costs less. So we can clearly say that the patient can have Amlong $10 \mathrm{mg}$ as their cost effective therapy.

Figure 1 shows the known history 78(65\%) and unknown history $42(35 \%)$ of hypertension. Most of the known history patients were already on treatment. Because hypertension is the number one health related problem all around the globe.

Figure 2 illustrates the persistence patterns for class of drugs prescribed at enrollment. In which $28(23.33 \%)$ of patients with amlodipine continued the treatment, $5(4.2 \%)$ switched and 6(5\%) discontinued the treatment. 17(14.2\%) of patients with Telma $\mathrm{H}$ were continuers, $6(5 \%)$ were switchers and discontinuers. This data suggest that most of the patients continued amlodipine may be due to its low cost and thereby it is affordable to the patient for a long term therapy.

Figure 3 which shows that amlong $5 \mathrm{mg}$ tablet costs for rupees 2.65 per tablet and amlong $10 \mathrm{mg}$ costs for rupees
5.33 and telma $\mathrm{H} \mathrm{40/12.5} \mathrm{mg,telma} \mathrm{H} 80 / 12.5$ mg costs for 14.73 and 22.36 rupees respectively. This data states that the most of the patients are continuing with the amlong $5 \mathrm{mg}$ because those patients having a lesser burden to the medication due its low annual average cost (48.41) followed with the amlong $10 \mathrm{mg}$ (annual average cost is 277.85) and very least patients are continuing with the telma $\mathrm{H}$ drugs may be due to its larger burden to the patient.

\section{CONCLUSION}

This study concluded that monotherapy of amlodipine is the most cost effective therapy than combination therapy of Telma $\mathrm{H}$ in order to reduce financial burden to the patient as well as to decrease the complications.

\section{ACKNOWLEDGEMENTS}

We express our sincere thanks to Dr. H.Doddayya, Principal, N.E.T Pharmacy College, Raichur, for his valuable help and providing necessary facilities to carry out this project and Dr. Ashok Mahendrakar, Medical Superintendent, NMCH\&RC, Raichur who had permitted us and provided us with the facilities to execute this work

We also record our special gratitude to all physicians and all nurses

\section{CONFLICT OF INTEREST}

NIL

\section{REFERENCES}

1. Mekonnen HS, Gebrie MH, Eyasu KH, Gelagay AA. Drug adherence for antihypertensive medications and its determinants among adult antihypertensive patients in chronic clinics of referral hospitals in Northwest Ethiopia. Mekonnen et al. BMC Pharmacol and toxicol, 2017; 18(27):1-10

2. Bhusal A, Jadhav PR, Deshmukh YA. Assessment of medication adherence among hypertensive patients: a cross-sectional study. Int J basics Clin Pharmacol, 2016; 5(4):1606-1612.

3. Bolivar JJ. Essential Hypertension an approach to its etiology and neurogenic pathophysiology. Int J Hypertens, 2013; 2013:1-11.

4. Alefan Q, Tariq AR, Ibrahim MI, Ayub A. Cost effectiveness of antihypertensive treatments in Malaysia. Malaysian J pharm sci, 2009; $7(2): 137-152$.

5. Ilesanmi OS, Kehinde Ige O, Adebiyi AO. The managed hypertensive: the costs of blood pressure control in Nigeria town. Pan Afr Med J. 2012; 12(96):1-9.

6. Dhivya PS, Swathy G, Siddhartha P. Pharmacoeconomics of antihypertensive drugs prescribed in a multispeciality hospital in South India. Asian j pharm, 2014; 8:178-182.

7. Esposti LD, Martino MD, Saragoni S, Sgreccia A, Capone A, Buda S, Esposti ED. Pharmacoeconomics of antihypertensive drug treatment: An analysis of how long patients remain on various antihypertensive therapies. The J Clin Hypertens, 2004; 6(2):76-83. 